Article

\title{
An Insight into Chemistry and Structure of Colloidal 2D-WS Nanoflakes: Combined XPS and XRD Study
}

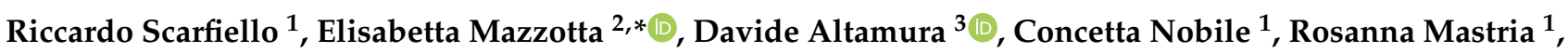

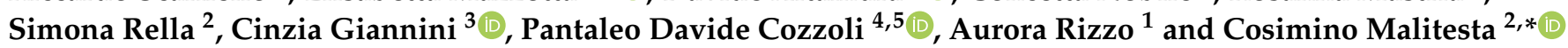 \\ 1 Institute of Nanotechnology, Campus Ecotekne, CNR NANOTEC, via Monteroni, 73100 Lecce, Italy; \\ riccardo.scarfiello@nanotec.cnr.it (R.S.); concetta.nobile@nanotec.cnr.it (C.N.); \\ rosanna.mastria@nanotec.cnr.it (R.M.); aurora.rizzo@nanotec.cnr.it (A.R.) \\ 2 Department of Biological and Environmental Sciences and Technologies, Campus Ecotekne, \\ University of Salento, via Monteroni, 73100 Lecce, Italy; simona.rella@unisalento.it \\ 3 Institute of Crystallography, IC CNR, via Amendola 122/O, 70126 Bari, Italy; davide.altamura@ic.cnr.it (D.A.); \\ cinzia.giannini@ic.cnr.it (C.G.) \\ 4 Department of Mathematics and Physics “E. De Giorgi”, Campus Ecotekne, University of Salento, \\ via Arnesano, 73100 Lecce, Italy; davide.cozzoli@unisalento.it \\ 5 UdR INSTM di Lecce, c/o, Campus Ecotekne, Universy of Salento, via Arnesano, 73100 Lecce, Italy \\ * Correspondence: elisabetta.mazzotta@unisalento.it (E.M.); cosimino.malitesta@unisalento.it (C.M.)
}

check for updates

Citation: Scarfiello, R.; Mazzotta, E.; Altamura, D.; Nobile, C.; Mastria, R.; Rella, S.; Giannini, C.; Cozzoli, P.D.; Rizzo, A.; Malitesta, C. An Insight into Chemistry and Structure of Colloidal 2D-WS 2 Nanoflakes: Combined XPS and XRD Study. Nanomaterials 2021, 11, 1969. https:// doi.org/10.3390/nano11081969

Academic Editor: Ki Kang Kim

Received: 4 June 2021

Accepted: 24 June 2021

Published: 30 July 2021

Publisher's Note: MDPI stays neutral with regard to jurisdictional claims in published maps and institutional affiliations.

Copyright: (c) 2021 by the authors. Licensee MDPI, Basel, Switzerland. This article is an open access article distributed under the terms and conditions of the Creative Commons Attribution (CC BY) license (https:// creativecommons.org/licenses/by/ $4.0 /)$.
Abstract: The surface and structural characterization techniques of three atom-thick bi-dimensional $2 \mathrm{D}-\mathrm{WS}_{2}$ colloidal nanocrystals cross the limit of bulk investigation, offering the possibility of simultaneous phase identification, structural-to-morphological evaluation, and surface chemical description. In the present study, we report a rational understanding based on X-ray photoelectron spectroscopy (XPS) and structural inspection of two kinds of dimensionally controllable 2D-WS 2 colloidal nanoflakes (NFLs) generated with a surfactant assisted non-hydrolytic route. The qualitative and quantitative determination of $1 \mathrm{~T}^{\prime}$ and $2 \mathrm{H}$ phases based on $\mathrm{W} 4 \mathrm{f}$ XPS signal components, together with the presence of two kinds of sulfur ions, $\mathrm{S}_{2}{ }^{2-}$ and $\mathrm{S}^{2-}$, based on $\mathrm{S} 2 \mathrm{p}$ signal and related to the formation of $\mathrm{WS}_{2}$ and $\mathrm{WO}_{\mathrm{x}} \mathrm{S}_{\mathrm{y}}$ in a mixed oxygen-sulfur environment, are carefully reported and discussed for both nanocrystals breeds. The XPS results are used as an input for detailed X-ray Diffraction (XRD) analysis allowing for a clear discrimination of NFLs crystal habit, and an estimation of the exact number of atomic monolayers composing the $2 \mathrm{D}-\mathrm{WS}_{2}$ nanocrystalline samples.

Keywords: transition-metal dichalcogenides; $\mathrm{WS}_{2}$ nanoflakes; $\mathrm{WS}_{2}$ colloidal nanocrystals; $\mathrm{X}$-ray photoelectron spectroscopy; X-ray diffraction; Debye function

\section{Introduction}

Bidimensional transition-metal dichalcogenides (2D-TMDs) are nontoxic and earth abundant lamellar solids made of van-der-Waals (vdW) stacked atomic layers, with the general formula $\mathrm{MX}_{2}$ (e.g., $\mathrm{M}=\mathrm{Mo}, \mathrm{W}, \mathrm{Ti} ; \mathrm{X}=\mathrm{S}$, Se, Te). Each individual layer of 2DTMDs is three atom-thick, being the metal atom sandwiched between two chalcogens. Depending on the atomic stacking configuration, $\mathrm{MX}_{2}$ compounds can form different crystal structures. The most commonly encountered polymorphs are the hexagonal close packing and trigonal prismatic coordination $(2 \mathrm{H})$ phase and the tetragonal symmetry and octahedral coordination phase $(1 \mathrm{~T})$ or its distorted polimorph $\left(1 \mathrm{~T}^{\prime}\right)$ [1-3]. The properties of different polymorphs differ significantly from one another. For example, in the case of $\mathrm{WS}_{2}, 2 \mathrm{H}-\mathrm{WS}_{2}$ monolayers are semiconducting with a direct band gap of about $2 \mathrm{eV}$, whereas their $1 \mathrm{~T}-\mathrm{WS}_{2}$ and $1 \mathrm{~T}^{\prime}-\mathrm{WS}_{2}$ counterparts possess a metallic character [4]. Moreover, in the form of ultrathin 2D nanostructures, in the mono- to few-layer regime, 2D-TMDs exhibit peculiar thickness-dependent properties, making them extremely attractive for several applications, spanning from optoelectronic and electronic devices to batteries and hydrogen-evolving photocatalysts [1,2,4-11]. 
Among various TMDs, $\mathrm{WS}_{2}$ attracts great attention for its plentiful prerogatives starting from large spin-orbit interaction [12] which offers a versatile platform for spin and valley physics studies as well as for being potentially employed for stimulated emission $[13,14]$, microlasers production [15] and generally promising for ultrafast optics as a high-power flexible saturable absorber material. The application of a high-power pulsed laser [16] and innovative optoelectronic devices such as photodetectors [7] and light emitting transistors [17] may substantially benefit from $2 \mathrm{D}-\mathrm{WS}_{2}$ features. Earth-abundant non-toxic $2 \mathrm{D}-\mathrm{WS}_{2}$ with high concentration metallic edges has been reported as platinumbased co-catalysts efficient while cheaper competitor in hydrogen evolution electrocatalysis at low working over-potentials [18]. Besides electrocatalysis, $2 \mathrm{D}-\mathrm{WS}_{2}$ nanosheets have been investigated for NIR light as well as strong UV-Vis light photocatalytic activity, indicating nanostructured 2D-WS 2 as a valuable full solar-spectrum photocatalyst [19]. Moreover, solution dispersible $2 \mathrm{D}-\mathrm{WS}_{2}$ based quantum dots, with an average size about $3 \mathrm{~nm}$, due to their optical features, good cell permeability, and low cytotoxicity, have been indicated as promising and biocompatible probes for in vitro bio-imaging [20]. Thus, the versatility and the broad applicability have attracted the interest of the scientific community in 2D-WS 2 nanostructures' controllable production and characterization over the years.

Nowadays, one of the most intensively pursued goals towards device integration is attaining single to few-stacked atomic thick $2 \mathrm{D}-\mathrm{WS}_{2}$ with solution processability, in order to obtain high quality thickness controllable sheets overtaking expensive vacuum depositions and substrate matched growth conditions which would eventually limit their mass fabrication [8]. The production of individually addressable, easily-processable $2 \mathrm{D}-\mathrm{WS}_{2}$ with controllable and uniform sub-nanometer thickness and tailored lateral dimensions is very challenging. The currently available repertory of $2 \mathrm{D}-\mathrm{WS}_{2}$ mostly comprises sheet-like nanostructures with irregular micrometer-scale lateral dimensions derived by liquid-phase exfoliation of corresponding bulk materials or by vapor-phase deposition on crystallographically oriented solid substrates [21].

Recently, wet-chemical synthetic approaches have emerged as powerful alternative routes to achieve morphologically and structurally controlled $2 \mathrm{D}-\mathrm{WS}_{2}$ in the form of robust free-standing nanostructures with finely adjusted geometric parameters, stabilized by organic ligands bound to their surface/edges and, hence, sufficiently stable in the liquid phase to be safely manipulated and transferred to applications [22-24].

In particular, in ref. [22], two different amine-based non-hydrolytic chemical pathways have been reported for dimensionally controlled and solution processable 2D-WS nanocrystals generated in the mono-to few layers thickness regime. A step-by-step investigation of morphological, structural, optical, and chemical evolution of two breeds of $2 \mathrm{D}-\mathrm{WS}_{2}$ nanoflakes generated into the two different amine-rich environments has been discussed. However, a more extensive and unambiguous chemical and structural understanding, based on X-ray Photoelectron Spectroscopy (XPS) and X-ray Diffraction (XRD), of as-prepared $2 \mathrm{D}-\mathrm{WS}_{2}$ nanocrystals, is essential for an in-depth study of such materials and represents the object of the present work.

The XPS technique has been indeed successfully used for the study of the chemical composition of transition metal dichalcogenides for obtaining information about their synthetic processes and/or their proposed application. For example, the extent of sulfidation process of some transition metals after treatment with sulfur vapor has been quantified by XPS analysis [25]. It has been also used for demonstrating the effective electron transfer between the $\mathrm{WS}_{2}$ and the $\mathrm{TiO}_{2}$ through S-O-Ti bonding in $2 \mathrm{D} \mathrm{WS}$ nanosheets decorated with $\mathrm{TiO}_{2}$ quantum dots used for ammonia gas sensing [26]. The content of amorphous $\mathrm{WO}_{3}$ in a few layer $\mathrm{WS}_{2}$ film has been evaluated by XPS analysis as well as its stabilization after the annealing procedure, allowing for postulating the role played by both $\mathrm{WS}_{2}$ and $\mathrm{WO}_{3}$ in the proposed gas sensing mechanism [27]. XPS analysis was also successfully used to compare the intrinsic air stability mechanism of several 2D transition metal dichalcogenides surfaces [28] evidencing different oxygen interaction processes at the basal plane and at the edges of the investigated materials, thus highlighting the importance of having 
controlled oxygen environment during crystal growth and defect passivation in order to provide high quality uniform materials for TMD-based device fabrication. In another work [29], the effect of the concentration of the reducing agent used during solution synthesis, 1,2-hexadecanediol, has been proven to significantly influence the final composition of TMDs. In some cases, XPS analysis has been also used to obtain structural information distinguishing $1 \mathrm{~T}-\mathrm{WS}_{2}$ and $2 \mathrm{H}-\mathrm{WS}_{2}$ structure [30,31] on the basis of $\mathrm{W} 4 \mathrm{f}$ core level peaks.

The XPS characterization of 2D-WS 2 NFLs that we report in the present work provides evidence on the $\mathrm{W}$ and $\mathrm{S}$ speciation giving additional information than expected based on the stoichiometric ratio. Also, information about the existence of two crystal phases, $1 \mathrm{~T} / 1 \mathrm{~T}^{\prime}$ and $2 \mathrm{H}$, has been inferred from XPS analysis. A single XPS peak for 1T/1T' phase has been observed, in agreement with XPS data on other TMDs [32]. Moreover, the comparison of XPS results on two kinds of $\mathrm{WS}_{2}$ NFLs prepared under different alkylamines reaction environment is reported, revealing that the chemical nature of the alkylamines, although having a key effect in modulating the lateral size of the resulting nanoflakes, does not induce any variation of the atomic scale structure and chemical composition. It should be highlighted that the XPS technique can be considered in this case as a bulk technique due to the few monoatomic layer structure of $2 \mathrm{D}-\mathrm{WS}_{2}$ NFLs thus enabling the investigation of the whole material thickness. Structural and chemical invariance are in turn confirmed through XRD characterization based on the Debye function calculation and are used as input data to reveal NFLs thickness variations. The full statistical representativity of sample features is achieved by the combination of the two non-local X-ray techniques, returning complementary volume averaged results.

\section{Materials and Methods}

\subsection{Chemicals}

Tungsten (VI) chloride $\left(\mathrm{WCl}_{6}, 99.9 \%\right)$, 1-octadecene $\left(\mathrm{C}_{18} \mathrm{H}_{36}\right.$ or ODE, $\left.90 \%\right)$, oleyl amine $\left(\mathrm{C}_{17} \mathrm{H}_{33} \mathrm{NH}_{2}\right.$ or $\left.\mathrm{OlAm}, 70 \%\right)$, and octyl amine $\left[\mathrm{CH}_{3}\left(\mathrm{CH}_{2}\right)_{6} \mathrm{CH}_{2} \mathrm{NH}_{2}\right.$ or OctAm, $\left.99 \%\right)$ were purchased from Sigma-Aldrich (Milan, Italy). All solvents used were anhydrous and of analytical grade. Chloroform, 2-propanol, and carbon disulfide $\left(\mathrm{CS}_{2}\right)$ were purchased from Sigma-Aldrich (Italy). Dried acetone $\left(\max 0.0075 \% \mathrm{H}_{2} \mathrm{O}\right)$ was purchased from SeccoSolv (Darmstadt, Germany). All chemicals and solvents were used as received without any further purification. OlAm and ODE were individually degassed at $80{ }^{\circ} \mathrm{C}$ for $1 \mathrm{~h}$, then repeatedly purged with nitrogen and stored in a $\mathrm{N}_{2}$-protected glovebox prior to use.

\section{2. $W S_{2}$ NFLs Synthesis}

$2 \mathrm{D}-\mathrm{WS}_{2}$ colloidal nanoflakes were synthesized as reported previously [22]. Briefly, $100 \mathrm{mg}(0.25 \mathrm{mmol})$ of $\mathrm{WCl}_{6}$ were loaded in three-neck flask under $\mathrm{N}_{2}$ atmosphere in a glovebox and dispersed in $1 \mathrm{~mL}(3.1 \mathrm{mmol})$ of degassed ODE. Then, $1 \mathrm{~mL}(3 \mathrm{mmol})$ of degassed OlAm or a mixture of $1 \mathrm{~mL}(3 \mathrm{mmol})$ of degassed OlAm and $1 \mathrm{~mL}(6 \mathrm{mmol})$ of OctAm were used to growth, respectively, $2 \mathrm{D}-\mathrm{WS}_{2}$ nanoflakes with lateral dimension $<5 \mathrm{~nm}$ or $\sim 25-30 \mathrm{~nm}$. NFLs synthesized in only OlAm environment is denoted as sample A, while NFLs synthesized in OlAm/OctAm 1:2 molar ratio environment is denoted as sample B. OlAm and OlAm/OctAm mixture volumes were adopted to fully disperse $\mathrm{WCl}_{6}$ obtaining an initially dark suspension which consequently converted into an optically clear yellow/reddish solution by stirring the mixture at room temperature. The whole system was further degassed (20 mTorr) for $1 \mathrm{~h}$ at $130^{\circ} \mathrm{C}$ and, after backfilling the reaction environment with dried $\mathrm{N}_{2}$ gas, a solution of $60 \mu \mathrm{L}(1 \mathrm{mmol})$ of $\mathrm{CS}_{2}$ in $2.5 \mathrm{~mL}(7.6 \mathrm{mmol})$ of degassed OlAm was swiftly injected into the mixture. The system was slowly heated (ramp rate of $\sim 5{ }^{\circ} \mathrm{C} / \mathrm{min}$ ) to $\sim 250{ }^{\circ} \mathrm{C}$ under $\mathrm{N}_{2}$ flow and aged at this temperature for 2 extra $h$. The reaction was quenched by removing the heating mantle and the solution was transferred at $\sim 40-50{ }^{\circ} \mathrm{C}$ into $\mathrm{N}_{2}$-protected glovebox for nanocrystals purification. For the aid, $15 \mathrm{~mL}$ of dried 2-propanol/acetone mixture $(2: 1 \mathrm{v} / \mathrm{v})$ were gently added to flocculate the $2 \mathrm{D}-\mathrm{WS}_{2} \mathrm{NCs}$ and discharge the unreacted reagents after centrifuging at $3000 \mathrm{rpm}$ for $10 \mathrm{~min}$. Two more cycles of dissolution in chloroform (or toluene) and re-precipitation with 
only acetone were also performed, obtaining fully dispersible samples in desired nonpolar solvents (toluene, chloroform), achieving an optically clear colloidal dark solution (sample A and sample B).

\subsection{XPS Characterization}

XPS measurements were recorded with an AXIS ULTRA DLD (Kratos Analytical, Manchester, UK) photoelectron spectrometer using a monochromatic AlK $\alpha$ source $(1486.6 \mathrm{eV})$ operated at $150 \mathrm{~W}(10 \mathrm{kV}, 15 \mathrm{~mA})$. The base pressure in the analysis chamber was $5.3 \times 10^{-9}$ torr. Survey scan spectra were recorded using a pass energy of $160 \mathrm{eV}$ and a $1 \mathrm{eV}$ step. High resolution spectra were acquired using a pass energy of $20 \mathrm{eV}$ and a $0.1 \mathrm{eV}$ step. In each case the area of analysis was about $700 \mu \mathrm{m} \times 300 \mu \mathrm{m}$. During the data acquisition a system of neutralization of the charge has been used. Processing of the spectra was accomplished by CasaXPS Release 2.3.16 software. The binding energy (BE) scale was referenced to the $\mathrm{Au} 4 \mathrm{f}_{7 / 2}$ peak at $84.0 \mathrm{eV}$. For the analysis of high resolution spectra all peaks were fitted using Shirley background and GL(30) lineshape (a combination of Gaussian 70\% and Lorentzian $30 \%$ ). For quantitative analysis, the relative sensitivity factors present in the library of CasaXPS for the areas of the signals were used. Surface charging was corrected considering adventitious C 1s (binding energies $(\mathrm{BE})=285 \mathrm{eV}$ ). For XPS analysis, samples were deposited by casting on an Au sheet.

\subsection{XRD Characterization}

XRD profiles were measured with a D8-Discover Bruker diffractometer (Bruker, Billerica, MA, USA) $(2.2 \mathrm{~kW})$ equipped with a $\mathrm{CuK} \alpha(\lambda=1.54 \AA$ Á) source (operated at $40 / 40 \mathrm{~mA} / \mathrm{kV}$ ), a Goebel mirror, a Eulerian cradle goniometer, and a scintillator detector. XRD patterns were collected at a fixed incident angle of $\alpha_{\mathrm{i}}=2^{\circ}$ while moving the detector with a step size of $0.05^{\circ}(2 \theta)$. Data were corrected for the fixed angular detector acceptance in the receiving slit detection mode, by multiplying the raw data by the width $(D)$ of the projected illuminated sample area $(L)$ at each $2 \theta$ angle: $D=L \times \sin \left(\pi-\alpha_{i}-2 \theta\right)$, being all angles expressed in radians.

Samples were prepared by spreading concentrated chloroform solutions of the aspurified colloidal NFLs on a silicon substrate in a glovebox. The substrate was then transferred to the diffractometer. All samples were measured under an ambient atmosphere at room temperature.

\subsection{TEM}

TEM investigation was performed with a JEOL JEM 1400Plus microscope (Tokyo, Japan), equipped with a GATAN Orius SC600 CCD (Pleasanton, CA, USA) camera and a tungsten filament-source operating at $120 \mathrm{kV}$. Samples were prepared by dropping an assynthesized $\mathrm{WS}_{2}$ nanoflakes dilute chloroform solution onto a carbon-coated copper grid.

\subsection{UV-Vis Absorptions}

UV-vis absorptions of freshly prepared and purified $2 \mathrm{D}-\mathrm{WS}_{2}$ nanoflakes $\mathrm{CHCl}_{3}$ solutions were recorded using a Varian Cary300 spectrophotometer (Agilent Technologies, Torino, Italy).

\section{Results}

We investigated solution casted 2D-WS 2 colloidal nanocrystals that were directly generated in liquid media under surfactant assisted synthetic protocol. In particular, we compared two breeds of $2 \mathrm{D}-\mathrm{WS}_{2}$ colloidal nanoflakes generated by a non-hydrolitic route in different high-boiling point alkylamine media reproduced from [22]. The different amine composition was found to be the key point to obtain a morphological and dimensional modification avoiding any other structural variation. Figure $1 \mathrm{a}, \mathrm{b}$ reports low resolution TEM images of solution casted chloroform solution of $\sim 3-5 \mathrm{~nm}$ (Figure $1 \mathrm{a}$, sample A) and $\sim 30 \mathrm{~nm}$ (Figure 1b, sample B) NFLs obtained in the different alkylamine environments. Both 
breeds of NFLs were characterized by an irregular and layered structure, hardly visible due to the low difference in contrast with carbon support grid in the low magnification TEM inspection (white line eye-guide in Figure 1a,b). Face-to-face stacked nanoparticles into short ribbon-like objects, which corresponded to the two-dimensional projections of nearly parallel standing nanocrystals, are evident in sample A (see white arrows in inset of Figure 1a).
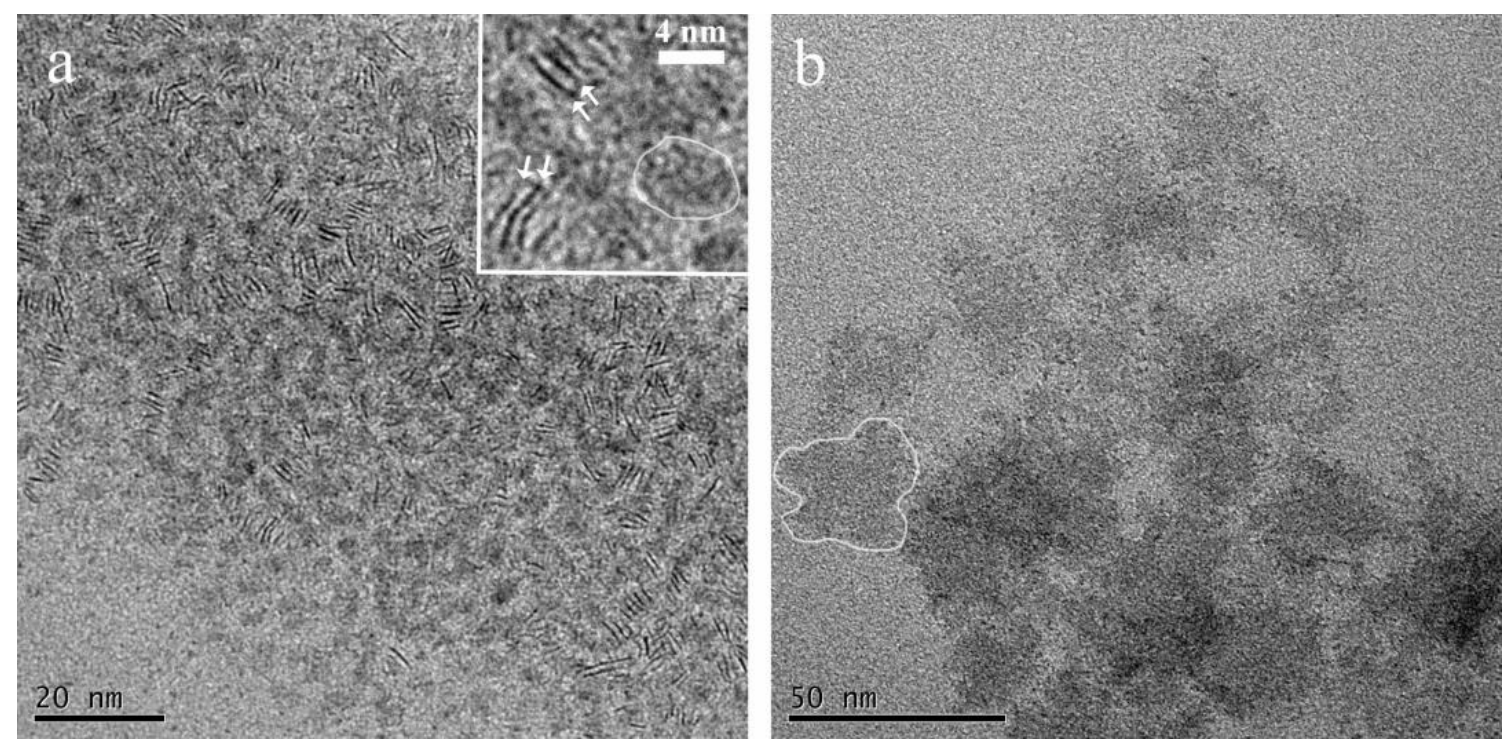

Figure 1. (a) Low resolution TEM of $\sim 3-5 \mathrm{~nm}$ (sample A) generated in OlAm rich environment and (b) $\sim 30 \mathrm{~nm}$ NFLs (sample B) generated in OlAm/OctAm 1:2 molar ratio environment.

\subsection{XPS Characterization}

The XPS detailed spectrum of W 4f signal of NFLs sample B is reported in Figure 2. As can be seen, the presence of both $2 \mathrm{H}$ and $1 \mathrm{~T} / 1 \mathrm{~T}^{\prime}$ forms can be evidenced [6], with the latter originating a single peak, as previously reported for other TMDs [32]. $1 \mathrm{~T}^{\prime}-\mathrm{WS}_{2}$ form is characterized by $\mathrm{W} 4 \mathrm{f}$ signal whose $\mathrm{W} 4 \mathrm{f}_{7 / 2}$ component is located at $31.6 \mathrm{eV}$. In the case

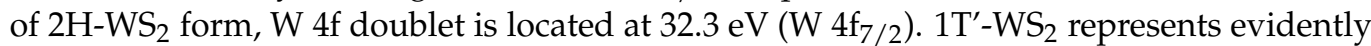
the most abundant form being its percentage equal to about $(56.8 \pm 5.4) \%$, while $2 \mathrm{H}-\mathrm{WS}_{2}$ form represents about $(27.0 \pm 6.4) \%$ of the investigated nanoflakes samples, as estimated by the area of XPS component signals. $\mathrm{WS}_{2}$ NFLs samples appear partially oxidized, as evidenced by the signals at $35.4 \mathrm{eV}$ and $37.5 \mathrm{eV}$, attributable, respectively, to $\mathrm{W} 4 \mathrm{f}_{7 / 2}$ and $\mathrm{W} 4 \mathrm{f}_{5 / 2}$ of $\mathrm{WO}_{\mathrm{x}}$ species. Note that the latter component is characterized by a higher area than what is expected for $4 f_{7 / 2}-4 f_{5 / 2}$ doublet as it also includes the contribution from the $\mathrm{W} 5 \mathrm{p}_{3 / 2}$ component [18]. The presence of $\mathrm{WO}_{\mathrm{x}}$ species could be due to post-synthesis surface oxidation [33] and represents $(18.4 \pm 2.1) \%$ of the $\mathrm{W}_{4 \mathrm{f}_{7 / 2}}$ signal ascribed to $1 \mathrm{~T}^{\prime}$ and $2 \mathrm{H}$ forms.

S 2p region (Figure 3) can be fitted into three components [31]. The intermediate doublet, denoted as " $\mathrm{A}$ " ( $\mathrm{S} 2 \mathrm{p}_{3 / 2}$ at $161.5 \mathrm{eV}$ ), could be ascribed to sulfur $\mathrm{S}^{2-}$ ions in $\mathrm{WS}_{2}$. Species at higher and at lower binding energy $\left(\mathrm{S} 2 \mathrm{p}_{3 / 2}\right.$ at $162.6 \mathrm{eV}$ and $160.9 \mathrm{eV}$, denoted as " $\mathrm{B}$ " and " $\mathrm{C}$ ") could be instead ascribed to two kinds of sulfur ions, $\mathrm{S}_{2}{ }^{2-}$ and $\mathrm{S}^{2-}$, respectively, related to the formation of $\mathrm{WO}_{\mathrm{x}} \mathrm{S}_{\mathrm{y}}$ in a mixed oxygen-sulfur environment, likely associated with $\mathrm{WO}_{\mathrm{x}}$ species identified in $\mathrm{W} 4 \mathrm{f}$ signal. It can be observed that the ratio between the doublet peaks of $S 2 p$ species at higher binding energy " $\mathrm{B}$ " is higher than the theoretical one (0.5). This could be due to the minor contribution of other sulfur species at higher oxidation states. The atomic ratio between $\mathrm{S} 2 \mathrm{p}$ and $\mathrm{W} 4 \mathrm{f}$ (considering the components related to $1 \mathrm{~T}^{\prime}$ and $2 \mathrm{H}$ phases) is equal to 2.2 , in good agreement with the theoretical one based on the stoichiometric ratio. 


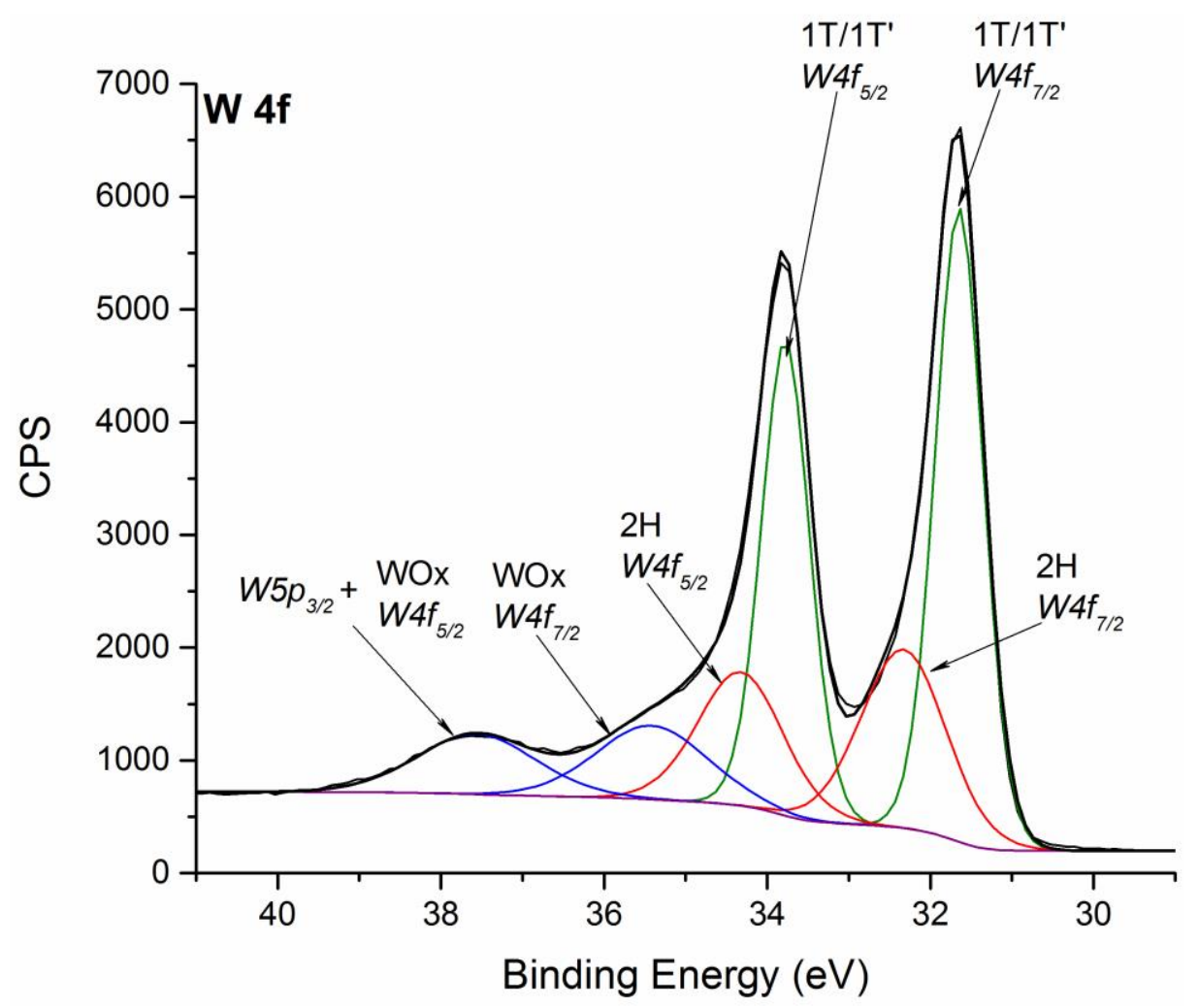

Figure 2. Fitted XPS spectrum of W $4 \mathrm{f}$ signal for $\mathrm{WS}_{2}$ NFLs sample B. Also, W 5p signal is reported. Spectrum is charging corrected. The same color is used for indicating doublet components.

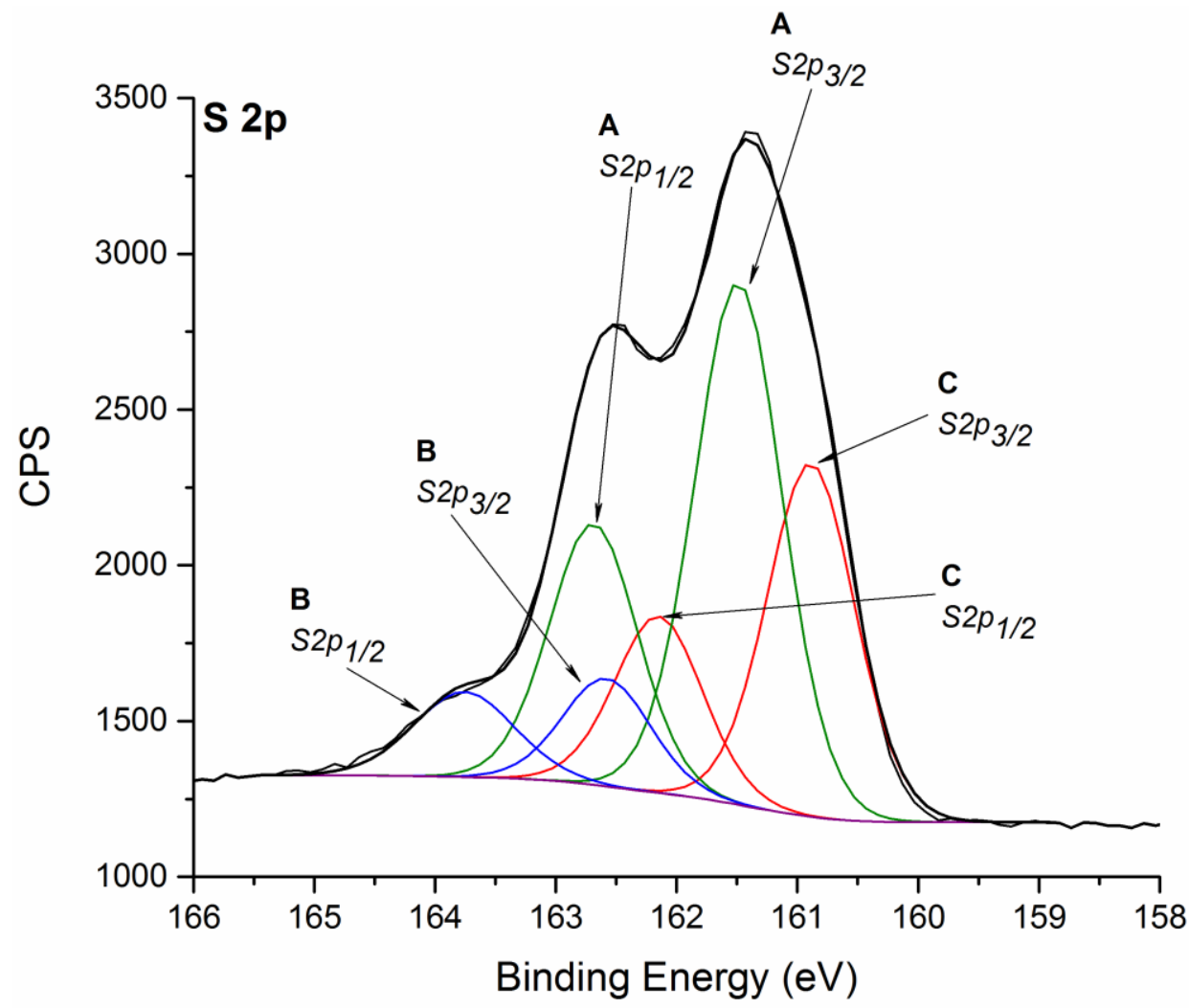

Figure 3. Fitted XPS spectrum of $\mathrm{S} 2 \mathrm{p}$ signal for $\mathrm{WS}_{2}$ NFLs sample B. Spectrum is charging corrected. Please see the text for the interpretation of peak doublet signals marked as A, B and C. The same color is used for indicating doublet components. 
The reported interpretation of sulfur signal is in agreement with literature XPS data identifying a single sulfur species for both $1 \mathrm{~T} / 1 \mathrm{~T}^{\prime}$ and $2 \mathrm{H} \mathrm{WS}_{2}$ crystal phases [18,34]. In some other cases, two distinct $S 2 \mathrm{p}$ components ascribed to $2 \mathrm{H}$ and $1 \mathrm{~T}$ phases are individuated $[35,36]$, but the quantitative estimation of their ratio is not in agreement with the ratio between $2 \mathrm{H}$ and $1 \mathrm{~T}$ phases estimated on the basis of $\mathrm{W} 4 \mathrm{f}$ signal.

The XPS analysis of $\mathrm{WS}_{2}$ NFLs samples A shows the same components for $\mathrm{W} 4 \mathrm{f}$ (Figure 4a) and S 2p (Figure 4b) signals as for sample B. These results evidence the high similarity in chemical composition of the two synthesized samples thus showing that the chemical nature and steric hindrance of the alkylamines are essential to modulate the reactivity of such $\mathrm{WS}_{2}$ nanoclusters, which correlate with the lateral size of the resulting nanoflakes, but do not induce any variation in the atomic structure and chemical composition.
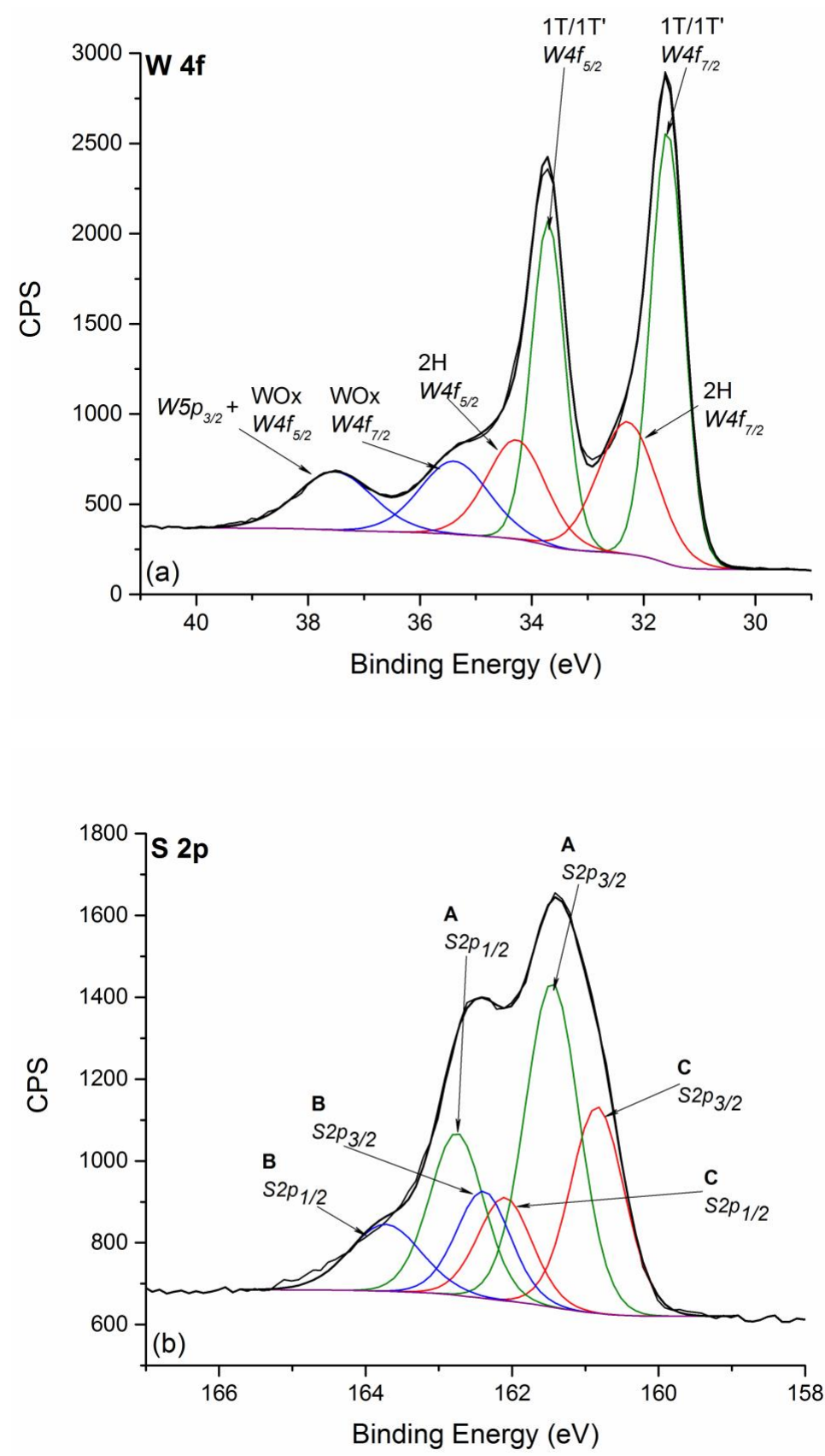

Figure 4. Fitted XPS spectra of W signal (a) and S 2p signal (b) for $\mathrm{WS}_{2}$ NFLs sample A. Spectra are charging corrected. In both spectra, the same color is used for indicating doublet components. 


\subsection{XRD Characterization}

Low magnification electron microscopy inspections reported in [22] evidenced that the different amine composition was found to be the key point to obtain a morphological and lateral dimensional modification avoiding any other evident structural variation. The obtained breeds NFLs presented in fact different lateral size $(\sim 3-5 \mathrm{~nm}$ for NFLs here denoted as sample A and $\sim 30 \mathrm{~nm}$ for sample B) and were both characterized by irregular and ultrathin layered structure. Experimental XRD data (Figure 5a), analogous to those in Figures $1 \mathrm{f}$ and $4 \mathrm{e}$ of ref. [22], feature a convolution of multiple peaks, due to the characteristic broadening for nano-scale structures of the analyzed systems. The mixed nature of the samples, which can be referred to $1 \mathrm{~T}^{\prime}$ and $2 \mathrm{H}$ phases, is visualized by the reference bars (dotted blue line for $1 \mathrm{~T}^{\prime}$ and green solid line for $2 \mathrm{H}$ ) at the bottom, and is demonstrated through the relevant Debye function calculations in Figure $5 b, c$, as it will be further discussed in detail. The coexistence of $1 \mathrm{~T}^{\prime}$ and $2 \mathrm{H}$ phases with a given percentage mass ratio can be assumed based on XPS results, while the different features in the XRD patterns can be almost totally ascribed to NFLs thickness variations between samples A and B. Similarly, the undefined featureless optical profile of both samples, reported in Figure $5 \mathrm{~d}$, are also expected for a mixed semiconducting $2 \mathrm{H}$ and metallic $1 \mathrm{~T}^{\prime}$ phase combination.
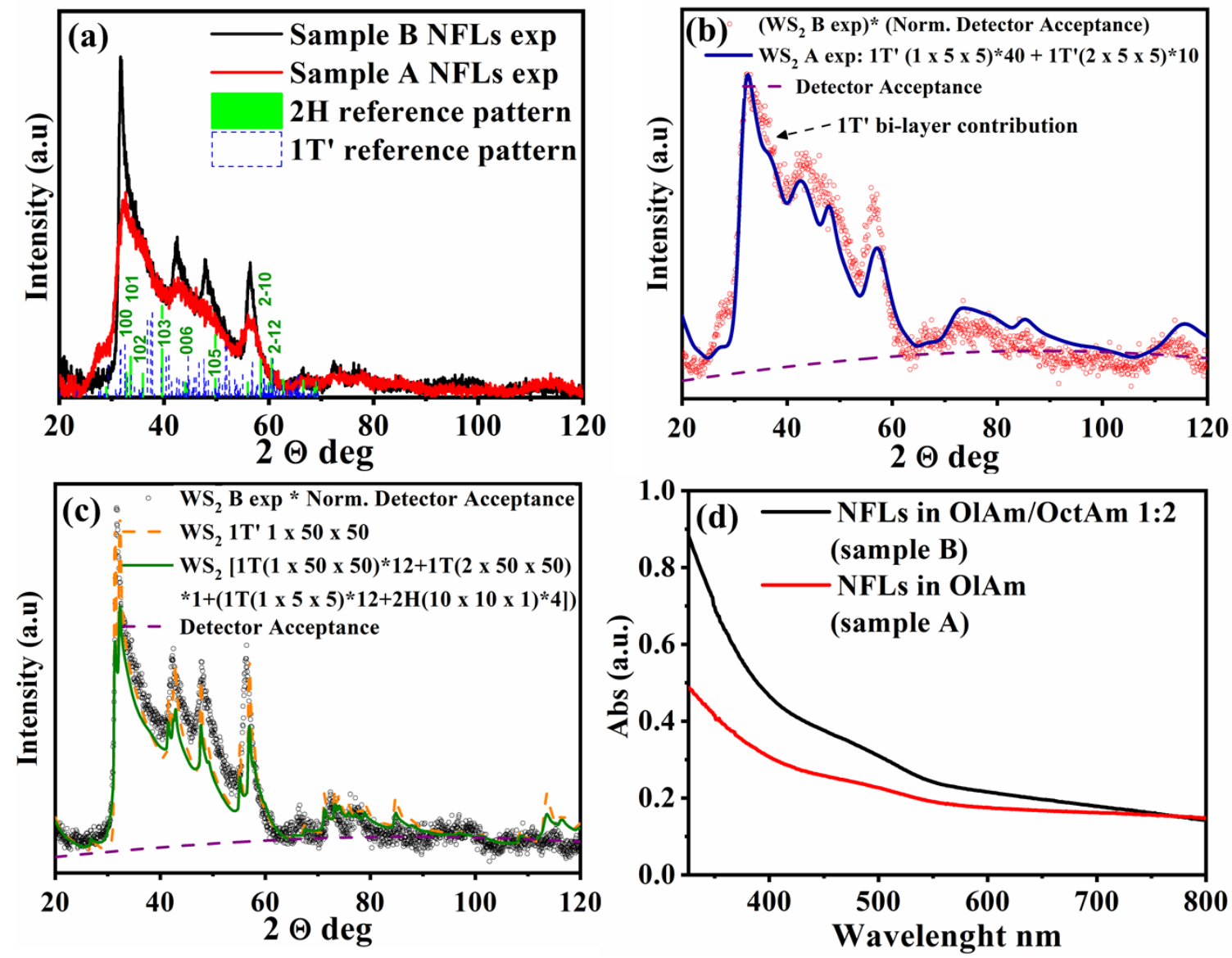

Figure 5. (a) Experimental XRD patterns (detector scans) of samples A ( $\sim 3-5 \mathrm{~nm}$ NFls obtained in sole OlAm) and sample B ( $\sim 30 \mathrm{~nm}$ NFLs obtained in OlAm/OctAm mixture in 1:2 molar ratio), with reference bars for $1 \mathrm{~T}^{\prime}$ and $2 \mathrm{H}$ crystal phases at the bottom. Only $2 \mathrm{H}$ main reflections are indexed for clarity; (b) experimental XRD pattern for sample A, reproduced from panel (a), with relevant Debye function calculation; (c) experimental XRD pattern for sample B, reproduced from panel (a), with relevant Debye function calculation. (d) UV-Vis absorption spectra of $\sim 3-5 \mathrm{~nm}$ (sample A, red) and $\sim 30 \mathrm{~nm}$ NFLs (sample B, black) $\mathrm{CHCl}_{3}$ solutions. 
Additionally, XPS quantification allowed us to refine Debye function calculations introduced in a previous work [22] and aimed at a general characterization of the average structure of 2D NFLs, involving $1 \mathrm{~T}^{\prime}$ and $2 \mathrm{H}$ crystal phases. Simulations of XRD patterns based on the Debye function allowed us to identify the main scattering contributions from NFLs with different size, shape and crystal structure $\left(1 \mathrm{~T}^{\prime}\right.$ or $\left.2 \mathrm{H}\right)$, identifying $1 \mathrm{~T}^{\prime}$ as the main crystal phase in the samples, consisting in one or two monolayers thick NFLs, independently of other a priori information [22]. Being XRD a typically non-local characterization technique, these results were statistically representative of the whole sample volume. On the other hand, no differentiation could be assessed between samples $\mathrm{A}$ and $\mathrm{B}$, due to the large number of variables taken into account. On the contrary, in the present analysis, we took advantage of XPS results by fixing the $1 \mathrm{~T}^{\prime}$ to $2 \mathrm{H}$ mass ratio, while only allowing NFLs size variation. The correlation between XPS and XRD analyses is ensured by the non-local character of both techniques, providing averaged results from macroscopic sample volumes leading to high statistical significance and representativity. The comparison between calculated and experimental XRD patterns for samples A and B are reported and compared in Figure $5 b, c$, respectively. Such profiles were selected after calculating several scattering profiles as linear combinations of profiles relevant to NFLs with different size and structure, similarly to what reported in ref. [22] (Figures S1 and S5 in ref. [22]). It was found that essentially no scattering contribution from $2 \mathrm{H}$ structures was necessary to obtain a good agreement between experiment and calculations, which can be explained based on the reference bars reported at the bottom of Figure 5a. Such bars represent indeed the structure factors (relevant to $1 \mathrm{~T}^{\prime}$ and $2 \mathrm{H}$ crystal structures) multiplied by the corresponding multiplicity factors, so as to obtain the final expected diffraction intensity: it can then be readily recognized that $1 \mathrm{~T}^{\prime}$ structure features many more and closer diffraction peaks (blue bars) than $2 \mathrm{H}$ one (green indexed bars); furthermore, $2 \mathrm{H} \mathrm{XRD}$ pattern features several high order diffraction peaks, the third index being the high order one, which are expected to be damped for a 2D lattice with its short dimension associated to the 001 reflections. As a consequence, the scattering contribution of $2 \mathrm{H}$ phase, also being a minority based on XPS results, is negligible compared to $1 \mathrm{~T}^{\prime}$.

Thus, it has been found that all scattering features could be mainly described by the only $1 \mathrm{~T}^{\prime}$ structure model in both samples: in particular, by $3 \mathrm{~nm}$ large and one or two monolayer thick NFLs in sample A (Figure $5 \mathrm{~b}$ ), and by $30 \mathrm{~nm}$ large and one monolayer thick NFLs in sample B (Figure 5c), expressed in terms of number of unit cells as $1 \times 5 \times 5$ (monolayers, $80 \%$ relative fraction) or $2 \times 5 \times 5$ (bilayers, $20 \%$ relative fraction) $1 \mathrm{~T}^{\prime}$ unit cells in NFLs of sample A, and $1 \times 50 \times 50$ (monolayers, $100 \%$ ) $1 \mathrm{~T}^{\prime}$ unit cells in NFLs of sample B. Minor discrepancies between experiments and calculations relevant to sample B can be ascribed to size dispersion and possibly to the weak $2 \mathrm{H}$ contribution.

\section{Conclusions}

A detailed investigation of the specific structural and chemical composition of 2D$\mathrm{WS}_{2}$ colloidal nanoflakes (NFLs) was performed by a combination of X-ray Photoelectron Spectroscopy and X-ray Diffraction analysis based on the Debye function calculation. After previously demonstrating the ability of achieving NFLs with lateral size of $\sim 3-5 \mathrm{~nm}$ and $\sim 30 \mathrm{~nm}$ by using, respectively, a single oleyl amine or a mixture of oleyl amine and octyl amine, in the present work, the similarity in chemical composition and the thickness differences between the two synthesized samples was verified, simulated, and discussed. These results show that the chemical nature and steric hindrance of the alkylamines are essential to modulate the reactivity of forming $\mathrm{WS}_{2}$ nanoclusters, which correlate with the lateral size of the resulting nanoflakes and with a bilayer vs. monolayer thick $1 \mathrm{~T}^{\prime}$ components in sample A (sample synthesized with only OlAm) and sample B (sample synthesized with OlAm:OctAm mixture) respectively. The effectiveness of XPS technique in providing information not only about chemical speciation but also about the existence of two crystal phases, $1 \mathrm{~T} / 1 \mathrm{~T}^{\prime}$ and $2 \mathrm{H}$, has been demonstrated, with the additional advantage of using XPS as a bulk technique in this case due to the few monoatomic layer structure 
of $2 \mathrm{D}-\mathrm{WS}_{2}$ NFLs. By relying on XPS results, further structural details have been obtained through $X$-ray diffraction-based experiment and modeling, revealing precisely the number of monolayers in the 2D NFLs. High statistical significance and representativity of sample features is ensured by the non-local character of the XPS and XRD techniques.

Author Contributions: Conceptualization, E.M., R.S. and C.M.; methodology, R.S., E.M., D.A. and A.R.; formal analysis, D.A. and C.G.; investigation, P.D.C., R.M. and C.N.; data curation, E.M. and C.M.; writing—original draft preparation, E.M. and R.S.; writing—review and editing, C.M., D.A. and C.G.; visualization, S.R. and C.N.; supervision, E.M. and C.M.; funding acquisition, A.R. and R.M. All authors have read and agreed to the published version of the manuscript.

Funding: This research was funded by Progetto FISR-C.N.R. “Tecnopolo di nanotecnologia e fotonica per la medicina di precisione"-CUP B84I18000540002; SIR project "Two-Dimensional Colloidal Metal Dichalcogenides based Energy-Conversion Photovoltaics" (2D ECO); SIR Project 2014 project number RBSI14-FYVD, CUP: B82I15000950008.

Institutional Review Board Statement: Not applicable.

Informed Consent Statement: Not applicable.

Conflicts of Interest: The authors declare no conflict of interest.

\section{References}

1. Radisavljevic, B.; Radenovic, A.; Brivio, J.; Giacometti, V.; Kis, A. Single-layer MoS 2 transistors. Nat. Nanotechnol. 2011, 6, 147-150. [CrossRef]

2. Chhowalla, M.; Shin, H.S.; Eda, G.; Li, L.J.; Loh, K.P.; Zhang, H. The chemistry of two-dimensional layered transition metal dichalcogenide nanosheets. Nat. Chem. 2013, 5, 263-275. [CrossRef] [PubMed]

3. Sokolikova, M.S.; Mattevi, C. Direct synthesis of metastable phases of 2D transition metal dichalcogenides. Chem. Soc. Rev. 2020, 49, 3952-3980. [CrossRef] [PubMed]

4. Wang, Q.H.; Kalantar-Zadeh, K.; Kis, A.; Coleman, J.N.; Strano, M.S. Electronics and optoelectronics of two-dimensional transition metal dichalcogenides. Nat. Nanotechnol. 2012, 7, 699-712. [CrossRef]

5. Hong, X.; Kim, J.; Shi, S.F.; Zhang, Y.; Jin, C.; Sun, Y.; Tongay, S.; Wu, J.; Zhang, Y.; Wang, F. Ultrafast charge transfer in atomically thin $\mathrm{MoS}_{2} / \mathrm{WS}_{2}$ heterostructures. Nat. Nanotechnol. 2014, 9, 682-686. [CrossRef]

6. Cheng, L.; Huang, W.; Gong, Q.; Liu, C.; Liu, Z.; Li, Y.; Dai, H. Ultrathin $\mathrm{WS}_{2}$ nanoflakes as a high-performance electrocatalyst for the hydrogen evolution reaction. Angew. Chem. Int. Ed. 2014, 53, 7860-7863. [CrossRef]

7. Perea-Lõpez, N.; Elías, A.L.; Berkdemir, A.; Castro-Beltran, A.; Gutiérrez, H.R.; Feng, S.; Lv, R.; Hayashi, T.; Lõpez-Urías, F.; Ghosh, S.; et al. Photosensor device based on few-layered $\mathrm{WS}_{2}$ films. Adv. Funct. Mater. 2013, 23, 5511-5517. [CrossRef]

8. Lv, R.; Robinson, J.A.; Schaak, R.E.; Sun, D.; Sun, Y.; Mallouk, T.E.; Terrones, M. Transition metal dichalcogenides and beyond: Synthesis, properties, and applications of single- and few-layer nanosheets. Acc. Chem. Res. 2015, 48, 56-64. [CrossRef]

9. Han, S.A.; Bhatia, R.; Kim, S.-W. Synthesis, properties and potential applications of two-dimensional transition metal dichalcogenides. Nano Converg. 2015, 2. [CrossRef]

10. Cao, X.; Tan, C.; Zhang, X.; Zhao, W.; Zhang, H. Solution-processed two-dimensional metal dichalcogenide-based nanomaterials for energy storage and conversion. Adv. Mater. 2016, 28, 6167-6196. [CrossRef] [PubMed]

11. Bhimanapati, G.R.; Lin, Z.; Meunier, V.; Jung, Y.; Cha, J.; Das, S.; Xiao, D.; Son, Y.; Strano, M.S.; Cooper, V.R.; et al. Recent advances in two-dimensional materials beyond graphene. ACS Nano 2015, 9, 11509-11539. [CrossRef] [PubMed]

12. Zhu, Z.Y.; Cheng, Y.C.; Schwingenschlögl, U. Giant spin-orbit-induced spin splitting in two-dimensional transition-metal dichalcogenide semiconductors. Phys. Rev. B Condens. Matter Mater. Phys. 2011, 84, 1-5. [CrossRef]

13. Lohof, F.; Steinhoff, A.; Florian, M.; Lorke, M.; Erben, D.; Jahnke, F.; Gies, C. Prospects and limitations of transition metal dichalcogenide laser gain materials. Nano Lett. 2019, 19, 210-217. [CrossRef]

14. Chernikov, A.; Ruppert, C.; Hill, H.M.; Rigosi, A.F.; Heinz, T.F. Population inversion and giant bandgap renormalization in atomically thin $\mathrm{WS}_{2}$ layers. Nat. Photonics 2015, 9, 466-470. [CrossRef]

15. Ye, Y.; Wong, Z.J.; Lu, X.; Ni, X.; Zhu, H.; Chen, X.; Wang, Y.; Zhang, X. Monolayer excitonic laser. Nat. Photonics 2015, 9, 733-737. [CrossRef]

16. Mao, D.; Wang, Y.; Ma, C.; Han, L.; Jiang, B.; Gan, X.; Hua, S.; Zhang, W.; Mei, T.; Zhao, J. WS 2 mode-locked ultrafast fiber laser. Sci. Rep. 2015, 5, 1-7. [CrossRef] [PubMed]

17. Jo, S.; Ubrig, N.; Berger, H.; Kuzmenko, A.B.; Morpurgo, A.F. Mono- and bilayer $\mathrm{WS}_{2}$ light-emitting transistors. Nano Lett. 2014, 14, 2019-2025. [CrossRef] [PubMed]

18. Voiry, D.; Yamaguchi, H.; Li, J.; Silva, R.; Alves, D.C.B.; Fujita, T.; Chen, M.; Asefa, T.; Shenoy, V.B.; Eda, G.; et al. Enhanced catalytic activity in strained chemically exfoliated $\mathrm{WS}_{2}$ nanosheets for hydrogen evolution. Nat. Mater. $2013,12,850-855$. [CrossRef] 
19. Sang, Y.; Zhao, Z.; Zhao, M.; Hao, P.; Leng, Y.; Liu, H. From UV to near-infrared, $\mathrm{WS}_{2}$ nanosheet: A novel photocatalyst for full solar light spectrum photodegradation. Adv. Mater. 2015, 27, 363-369. [CrossRef]

20. Xu, S.; Li, D.; Wu, P. One-pot, facile, and versatile synthesis of monolayer $\mathrm{MoS}_{2} / \mathrm{WS}_{2}$ quantum dots as bioimaging probes and efficient electrocatalysts for hydrogen evolution reaction. Adv. Funct. Mater. 2015, 25, 1127-1136. [CrossRef]

21. Elías, A.L.; Perea-López, N.; Castro-Beltrán, A.; Berkdemir, A.; Lv, R.; Feng, S.; Long, A.D.; Hayashi, T.; Kim, Y.A.; Endo, M.; et al. Controlled synthesis and transfer of large-area $\mathrm{WS}_{2}$ sheets: From single layer to few layers. ACS Nano 2013, 7, 5235-5242. [CrossRef]

22. Scarfiello, R.; Cesari, A.; Altamura, D.; Masi, S.; Nobile, C.; Balzano, F.; Giannini, C.; Grillo, V.; Tavabi, A.H.; Dunin-Borkowski, R.E.; et al. Mechanistic insight into the formation of colloidal $\mathrm{WS}_{2}$ nanoflakes in hot alkylamine media. Nanoscale Adv. 2019, 1, 2772-2782. [CrossRef]

23. Jeong, S.; Yoo, D.; Jang, J.T.; Kim, M.; Cheon, J. Well-defined colloidal 2-D layered transition-metal chalcogenide nanocrystals via generalized synthetic protocols. J. Am. Chem. Soc. 2012, 134, 18233-18236. [CrossRef]

24. Mastria, R.; Scarfiello, R.; Altamura, D.; Giannini, C.; Liscio, A.; Kovtun, A.; Bianco, G.V.; Bruno, G.; Grillo, V.; Tavabi, A.H.; et al. In-plane Aligned Colloidal 2D WS 2 Nanoflakes for Solution-Processable Thin Films with High Planar Conductivity. Sci. Rep. 2019, 9, 1-13. [CrossRef] [PubMed]

25. Simchi, H.; Walter, T.N.; Choudhury, T.H.; Kirkley, L.Y.; Redwing, J.M.; Mohney, S.E. Sulfidation of 2D transition metals (Mo, W, $\mathrm{Re}, \mathrm{Nb}, \mathrm{Ta}$ ): Thermodynamics, processing, and characterization. J. Mater. Sci. 2017, 52, 10127-10139. [CrossRef]

26. Qin, Z.; Ouyang, C.; Zhang, J.; Wan, L.; Wang, S.; Xie, C.; Zeng, D. 2D WS 2 nanosheets with TiO 2 quantum dots decoration for high-performance ammonia gas sensing at room temperature. Sens. Actuators B Chem. 2017, 253, 1034-1042. [CrossRef]

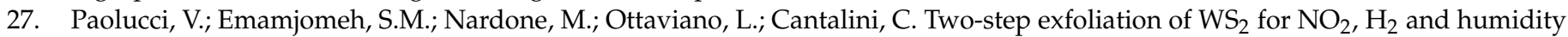
sensing applications. Nanomaterials 2019, 9, 1363. [CrossRef] [PubMed]

28. Longo, R.C.; Addou, R.; Santosh, K.C.; Noh, J.Y.; Smyth, C.M.; Barrera, D.; Zhang, C.; Hsu, J.W.P.; Wallace, R.M.; Cho, K. Intrinsic air stability mechanisms of two-dimensional transition metal dichalcogenide surfaces: Basal versus edge oxidation. $2 \mathrm{D}$ Mater. 2017, 4, 025050. [CrossRef]

29. Barrera, D.; Wang, Q.; Lee, Y.J.; Cheng, L.; Kim, M.J.; Kim, J.; Hsu, J.W.P. Solution synthesis of few-layer $2 \mathrm{H} \mathrm{MX} 2(\mathrm{M}=\mathrm{Mo}$, W.; $\mathrm{X}=\mathrm{S}$, Se). J. Mater. Chem. C 2017, 5, 2859-2864. [CrossRef]

30. Mahler, B.; Hoepfner, V.; Liao, K.; Ozin, G.A. Colloidal synthesis of $1 \mathrm{~T}-\mathrm{WS}_{2}$ and $2 \mathrm{H}-\mathrm{WS}_{2}$ nanosheets: Applications for photocatalytic hydrogen evolution. J. Am. Chem. Soc. 2014, 136, 14121-14127. [CrossRef]

31. Martin-Litas, I.; Vinatier, P.; Levasseur, A.; Dupin, J.C.; Gonbeau, D.; Weill, F. Characterisation of r.f. sputtered tungsten disulfide and oxysulfide thin films. Thin Solid Films 2002, 416, 1-9. [CrossRef]

32. Guo, C.; Li, H.; Zhao, W.; Pan, J.; Lin, T.; Xu, J.; Chen, M.; Huang, F. High-quality single-layer nanosheets of $\mathrm{MS} \mathrm{S}_{2}(\mathrm{M}=\mathrm{Mo}, \mathrm{Nb}$, Ta, Ti) directly exfoliated from $\mathrm{AMS}_{2}(\mathrm{~A}=\mathrm{Li}, \mathrm{Na}, \mathrm{K})$ crystals. J. Mater. Chem. C 2017, 5, 5977-5983. [CrossRef]

33. Sun, Y.; Fujisawa, K.; Terrones, M.; Schaak, R.E. Solution synthesis of few-layer WTe 2 and $\mathrm{Mox}_{1-\mathrm{x}} \mathrm{Te}_{2}$ nanostructures. J. Mater Chem. C 2017, 5, 11317-11323. [CrossRef]

34. Zhao, X.; Ma, X.; Sun, J.; Li, D.; Yang, X. Enhanced catalytic activities of surfactant-assisted exfoliated $\mathrm{WS}_{2}$ nanodots for hydrogen evolution. ACS Nano 2016, 10, 2159-2166. [CrossRef] [PubMed]

35. Ambrosi, A.; Sofer, Z.; Pumera, M. $2 \mathrm{H} \rightarrow 1 \mathrm{~T}$ phase transition and hydrogen evolution activity of $\mathrm{MoS}_{2}, \mathrm{MoSe}_{2}, \mathrm{WS}_{2}$ and $\mathrm{WSe}_{2}$ strongly depends on the $\mathrm{MX}_{2}$ composition. Chem. Commun. 2015, 51, 8450-8453. [CrossRef] [PubMed]

36. Toh, R.J.; Mayorga-Martinez, C.C.; Sofer, Z.; Pumera, M. 1T-phase $\mathrm{WS}_{2}$ protein-based biosensor. Adv. Funct. Mater. 2017, 27, 1-8. [CrossRef] 